\title{
Integrating medical humanities into physiotherapy and occupational therapy education
}

\author{
Sue Smith, Matthew Molineux, Nick Rowe, Louise Larkinson
}

This paper outlines an innovative curricular development at Leeds Metropolitan University. Two new programmes the MSc occupational therapy (OT) and MSc physiotherapy (PT) (preregistration) which have a strong element of shared learning in their curricula are running for their first year post approval.

Medical humanities $(\mathrm{MH})$ is frequently used as method of education with preregistration OT students and medical students (Hurwirz, 2003) but is much less commonly used in PT preregistration education. The OT and PT students jointly took part in a week of MH involving workshops, discussion and a 'performance' of work in progress. The week focused on the use of literature and the arts as a channel for exploration and discussion of human issues that are pertinent to health professionals. The aim was to help foster empathy, compassion and skills which the students would need to use on an everyday basis when dealing with a wide spectrum of service users and colleagues at the University and on practice placement.

The paper is sectioned chronologically. There is a review of the background literature and rationale for the development of MH in PT and OT cirricula. The external specialist tutors, the course leaders and the OT and PT students' views and input are outlined.

The $\mathrm{MH}$ week was evaluated through written evaluation forms, a student focus group, email comments from students to course leaders and a staff debriefing. Learning points for staff and students are addressed. Recommendations relating to the format, content and development ideas for implementation of $\mathrm{MH}$ education for future cohorts are proposed.

Key words: Physiotherapy, occupational therapy, medical humanities, education

Smith S, Molineux M, Rowe N, Larkinson L (2006) Integrating medical humanities into physiotherapy and occupational therapy education. Int J Ther Rehabil 13(9): 421-27

$\mathrm{H}$ ealth professionals are often confronted with great human distress. In the face of this they need to respond humanely and be able to address the questions raised by illness, disability and bereavement in a sensitive way. They need to consider difficult ethical issues and appreciate the complexity of an individual's response to ill health and misfortune. The capacity for empathy, compassion and sensitivity required for work as an allied health professional cannot easily be taught through traditional pedagogic methods. Textbooks are of only limited help since they strive to be systematic and generalist in their approach. Students need to be prepared for their challenging work.

One way in which health students can be helped to develop the necessary sensitivity, empathy and self-awareness for effective practice is to use literature and the arts as a means of exploring and discussing human issues pertinent to the health professional: an approach that is now often called medical humanities (MH) (Hurwitz, 2003).

MH was introduced into medical student education in order to balance the largely scientific content and to act as a vehicle for exploring the many dimensions of what it is to be human. It is now regularly included within the curricula of many health professions' training courses (Gull, 2005).

Chomsky (1972) argued that individuals will learn more about human life and personality from novels than from scientific literature. More recently, the novelist Lodge (2002) maintained that while science endeavours to formulate general and explanatory laws that apply universally:
Sue Smith is Principal Lecturer in Physiotherapy and, Matthew Molineux is Head of Occupational Science and Occupational Therapy, Faculty of Health, Leeds Metropolitan University, Leeds, LS13HE UK Dr Nick Rowe and Louise Larkinson are Senior Lecturers in the School of Professional Health Studies and Fellows of York St. John's Centre of Excellence in Teaching and Learning, York St. John University College, Lord Mayor's Walk, York

Correspondence to: S Smith 
'Works of literature describe in the guise of fiction the dense specificity of personal experience which is always unique because each of us has a slightly different or very different personal history.'

Arts and literature can help to develop and nurture skills of observation, imagination, intuition, empathy and self reflection. Downie (2003) suggests that the:

'Study of literature and humanities may not be able to make clinicians more humane but it can foster a depth of human and humane understanding, knowledge and experience.'

There is a wide range of literature supporting the benefits of including $\mathrm{MH}$ teaching in the education of health professionals (Box 1) (De Villiers 1993; General Medical Council Education Committee, 1993; Charon et al, 1995; McAteer and Murray, 2003; Staricoff, 2004). Robb and Murray (1992) with their exploration of $\mathrm{MH}$ in nursing and McNaughton's (2000) detailed overview of three medical courses' curricula provide a starting point for considering the practical issues of $\mathrm{MH}$ teaching. Overall, however, there is a paucity of literature which demonstrates conclusive evidence supporting how $\mathrm{MH}$ programmes should practically be structured and implemented.

Box 1. The claims made for the use of the arts in the training of health professionals

1. Develops an appreciation of the complexity of human experience. It promotes sensitivity to the subtlety of human experience. For example, De Villiers (1993) suggests that the poet's ability to work with complex thoughts can aid a doctor's appreciation of patient experience.

2. Promotes an appreciation, and sensitivity of difference.

For example, Charon et al (1995) and Hunter et al (1995) separately argue that literature can develop empathy across gender, race, class and culture.

3. Encourages a more complex appreciation of meanings that are attributed to illness, suffering, dying and grieving.

For example, McAteer and Murray (2003) provide evidence that physiotherapy students who worked with literature during a module on loss and grief performed better in the assessment than those who restricted themselves to scientific texts.

4. Engagement with works of art can enable students to make rich connections between personal experience and professional knowledge/ experience.

For example, students working on the theme of grief have been able to relate their own experience to the theoretical material available and to the clinical situations they may find themselves in. Art can act as a 'bridge' between theory and lived experience (Hurwitz, 2003).

5. Develops more sophisticated expressive and observational skills.

For example, through introducing students to selected portraiture they are asked to provide health assessments of the mental, physical and environmental circumstances of the characters (Inskeep and Lisko, 2001). The author claims that this increases skills of observation and descriptive capacities of nursing students.

\section{BEFORE THE MEDICAL HUMANITIES WEEK: THE COURSE TUTORS' VIEWS}

$\mathrm{MH}$ is frequently used in OT education to enhance reflective thinking among students and practitioners (Murray et al, 2000). However, there is not a strong tradition of $\mathrm{MH}$ being integrated within PT courses. However, the development of the new courses at Leeds Metropolitan University with a strong ethos of shared learning between the OTs and PTs provided the catalyst for a change in thinking.

These courses have adopted a problem-based learning approach as their educational philosophy. As a result the integrated realistic nature of the problems and/or triggers employed ensured that group working, psychosocial, professional and physical issues offered an ideal educational context for a new MH component to be developed

There were a number of key concerns and assumptions highlighted by the course tutors before the MH week, and are as follows:

\section{Potential anxiety of students}

It was assumed that most of the students would have done little creative writing, acting or poetry analysis since they were at school and they may be terrified of the process. It appears that medical students read less while at university than they did before they got there (Gull, 2005) and it was assumed this might apply to the PT and OT students. These ideas are reflected by Gull (2005) who discusses issues around reading and the arts and the extent to which it should be compulsory or if the choice of material in $\mathrm{MH}$ curricula should be student led.

There was a concern from the tutors choosing the themes and books that there might be a problem of prescription and of turning off the students from the very processes being encouraged. A decision was made to offer considerable choice and flexibility to the students in terms of the theme choice they made and the reading material they employed.

\section{The position of the MH week in the course: early or later?}

There was considerable debate around the citing of the $\mathrm{MH}$ component in the new courses. If the week came early on in the course, it might upset the flow of the early modules of both courses (a core movement and function module for the PT students, and the module humans as occupational beings for the OT students). However, on the other hand, it sets the right tone for a holistic, social model of practice for both physiotherapists and OT. If the $\mathrm{MH}$ was situated later in the courses, the students might have become more professionally socialized by then but may also have reduced academic pressure on them by that stage in their courses which may enable 
them to have more time and energy to enjoy the $\mathrm{MH}$ work more. After discussion, the $\mathrm{MH}$ week was placed in week 7 , early in the course.

\begin{abstract}
Attendance
There were concerns that the students would not attend, or would view it as time to write their concurrent module assignment or not regard the work as 'real PT' or 'real OT'. Attendance was compulsory for all modules because of professional body requirements. $\mathrm{MH}$ was integrated into both courses" initial modules to send the right message that it was a formal, integrated and compulsory part of the course.

Concerns were also raised that some of the students may not attend because they feared exploring some of the themes. Tutors discussed the need to support the students effectively if they found the emotional element of the week difficult to deal with.
\end{abstract}

\section{Relevance to the professions}

There were fewer concerns about its relevance to the professional requirements of the PT and OT professional bodies. The Health Professions Council (HPC, 2003) Standards of Proficiency, the Chartered Society of Physiotherapy's (CSP) (2002, 2003) curriculum framework and the College of Occupational Therapists (COT), (2004) curriculum framework and standards emphasize the importance of designing preregistration qualifying curricula to meet the holistic and reflective nature of practice.

The creative and social element and the strong emphasis on reflection and interpersonal skills reflected the core generic learning outcomes for both courses.

\section{RUNNING THE WEEK: THE EXTERNAL SPECIALIST TUTORS' VIEWS}

\section{Group working using drama and literature}

Students' own experience of the arts needed to be valued and foregrounded, so they were asked to bring a passage of literature or a sequence from a film for the first session. They were to choose something that had enhanced their insight into the human condition and/or into issues related to health, illness or disability. The structure of the MH week is outlined in Box 2. During the first day the students worked with these in order to explore, through writing and drama, the impact the work had on them personally and professionally.

During the remaining 3 days they were invited to choose one of four 'theme groups':

Grief and bereavement

Transitions in the life course

Relationships

Isolation/loneliness.
These themes were chosen for their relevance to the human condition, it was felt essential that the students did not confine their explorations too narrowly to health issues and the experiences of individual clients. Instead they were encouraged to think broadly about how the works given to them and those they brought with them provided an insight into what it was to be human and, as importantly, how they related this to their own personal and professional experience (See Box 3 and 4 for examples of some of the work used by students). In all of the groups there was a remarkable willingness to think widely and to bring their own life experiences to the exploration of the work (See Box 5 for the key underpinning learning principles for the week)

\section{Working towards a performance}

The students also had another task, to deliver a performance on the final day. Although inevitably this put additional pressure on them, it was considered worthwhile because it encouraged the students to:

Take 'ownership' of the work they were doing; it permitted them to bring the art work 'closer' and to avoid the kind of distancing that is a feature of more 'academic' approaches. To put this another way, the students were asked - and were able to - embody the work

\section{Box 2. Outline of structure of MH week}

Day 1. Reviewing literature, art and film- workshop. Whole and small group work looking at identified themes ('theme groups': grief and bereavement; transitions in the life course; relationships, and isolation/loneliness).

Day 2. Workshop around chosen themes.

Day 3. Small group work and rehearsal of work in process.

Day 4. Rehearsal and 'performance' of work in progress.

\section{Box 3. Example: medical humanities text used}

From Susan Hill's novel In the Springtime of the Year (Hill, 2005), which traces Alice's grief after losing her husband in a tragic accident, the students were given the following section:

'She had not thought. It was so obvious and yet she had not expected it. She took them out one by one, these clothes in which he had died, the blue shirt and the dark woollen jersey, the corduroy trousers and thick socks, and lifted each one up, wanting to smell, beneath the wool or cotton, his own smell. She did not, and then realised that the things had been newly washed and ironed. She put her head down and pressed her face into the pile of garments and at last the grief broke open and drowned her, for they had taken even that away from her, they had washed away his blood and now, she understood fully and finally that Ben was dead and gone from her, that she had nothing, nothing left.'

Students used this passage and others to talk about the painful and gradual realization of loss. During this they talked of the professional insights this passage offered as well as their personal experience of grief. 
It was a means through which the students could share their work with each other and with the staff

- The performance provided a structure that 'contained' the students' personal and professional exploration and a 'closure' to their work.

\section{VIEWS OF THE MSC OT AND PT (PREREGISTRATION) STUDENTS}

Student views were evaluated via written evaluation forms at the end of the week through whole group verbal feedback after the performance and via student volunteers for separate course focus groups.

\section{Value}

There was a strong initial sense that the students were too busy to bother with something they

\section{Box 4. Example of poem used during medical humanities week}

A poem by Fanthorpe (2005) which explores the isolated world of loneliness and depression:

Inside our coloured, brisk world,

Like a bone inside a leg, lies

The world of the negative.

It is the same world, only somehow Conviction has dribbled out of it, Like stuffing from a toy.

A world of hypnotic clocks and unfinished Goblin gestures. Nothing moves in a landscape Fixed in hysteria's stasis.

This is the hushed network of nightmare. You have lost touch with the sustaining Ordinariness of things.

Suddenly the immense and venerable Fallacies that prop the universe Fail, the colossal flickering fabric Which we must believe in so that it can be Goes out.

Here malevolence is routine, the shadow Is real and the world is shadow. Here the happy-ever-after crumples Into a rheumatoid hic-iacet.

Here the appalling and unexpected Disaster is expected. Here the blood Screams whispers to the flesh.

And here the alien wanders

Endless benighted streets where innocent households Laugh behind blinds and believe in tomorrow

Like the milkbottles at the door.

The students analysed this poem and looked at the issues it raised for them professionally and personally around the subject of loneliness, despair and depression. They also considered it in relation to groups in society that are often marginalized and subjected to prejudice. One student chose to recite it as part of the performance. regarded as an additional 'bolt on'. They perceived they had more important groundwork on their basic profession specific knowledge and skills. There was a sense that it almost complemented rather than was integral to their sense of professional identity:

'We thought it was a waste of time initially cos it was right in the middle of our first anatomy and movement module and we really wanted to get to grips with that.' (PT student)

'I think later in the course would be better when we have got more into our physio stride.' (PT student)

The OT students seemed slightly more open to the value of the week. Several students thought the week was enjoyable and useful and one commented that:

"It allowed us as a group to focus on the human rather than the condition.' (OT student)

One student went so far to say that:

'I feel the week was a bit underrated.'

(OT student)

\section{Performing}

There was some anxiety about what the week might entail and whether the students would be forced to act in public when they didn't want to:

'I enjoyed it when I got going and realized I wouldn't be forced to perform.' (PT student)

'It was less a question of what I knew for the first time more an interest in what my thoughts were.' (PT student) 'I was very nervous about the week, and when acting out the scenes on the Friday, however, I did enjoy the experience and thought it was helpful.' (OT student)

\section{Box 5. Underpinning learning principles} for the week

1. The literature relating to medical humanities suggests that it is important that students integrate the work into their understanding of theory and their experience on clinical

2. The students were both professionally and personally engaged with the material.

3. The structure of the sessions provided a safe space for personal exploration.

4. The students were able to take 'ownership' of the work and to demonstrate a commitment to it.

5. The opportunity to process the educational value of the work was integrated into the sessions. 
The students admitted to relaxing during the week and starting to see the relevance of it more. They started to tap into creative skills that previously had been under-used. For example, script writing, using different voices and speech patterns and directing the performance.

\section{The chosen themes}

The themes had been prearranged by the tutors and the course leaders to fit with the learning outcomes of the modules. There was little disagreement with the relevance and appropriateness of the chosen themes (social isolation, grief and loss, relationships, and transitions in the life course) Students could choose the group theme they worked with:

'There were some good ideas. The

themes had already been set but we worked on loneliness and social isolation and thought about what it was like to be old and cut off from things and how that might affect your health.' (PT student)

\section{Learning together}

The MSc PT (preregistration) and MSc OT (preregistration) courses had a strong ethos of shared learning and generally the students accepted this and could see the value of sharing the experience with another professional group:

'We met and worked with the OTs and learned how they worked. They are more arty than us I think.' (PT student)

\section{'I think we realized after a day or so that we could be creative after all.' (PT student)}

'It was good to work with others in OT and in Physio.' (OT student)

\section{The place for $\mathrm{MH}$ in the courses}

The students generally felt that the $\mathrm{MH}$ week was not well placed in the modules/courses. For many this was because of other pressures, such as preparing for imminent assessments:

'I think the week was a really good idea but the timing was bad. Everyone was too stressed with their assessments to put enough into it.' (OT student)

For a small group of students it was the emotional nature of the week which made it difficult:

'It was emotionally draining and I found it impossible to focus on any other work during this week.' (OT student)

The PT students stated that they would like MH situated later in the MSc PT course primarily so they could use some of the experiences they had gained on practice placement. However, they clearly understood the reasons why MH was put it earlier in the programmes:

'I can see why they wanted to put it early in the course because it sets the right tone you know... The right note. Physio is not all about anatomy but these big social issues and understanding people as well.' (PT student)

\section{AFTER THE MH WEEK: REVIEWING WHAT HAPPENED}

Early in the OT and PT programme or later?

$\mathrm{MH}$ courses and teaching vary in length and design and most research describes its teaching on medical courses. Some MH education is structured as full modules (Evans and Greaves, 1999) and others vary from voluntary evening run sessions or a 90 -minute compulsory single session (McNaugton, 2000).

The authors' week-long MH teaching was situated early in the course. The aim of this, supported by De Villiers, (1993) was to clearly indicate to the students of both courses that understanding one's emotional responses to situations was vital from the very beginning when preparing to be an effective practitioner.

The students were evaluated on the $\mathrm{MH}$ programme. The students stated that they had only just got going on their first profession specific module and were just starting to accommodate to problem-based learning as an approach. They felt it interrupted their 'flow', reduced their focus on fundamental 'pure' professional modular issues and was too close to their first assessment week.

\section{One week or separate days?}

The intense week long model adopted during this provision was regarded as advantageous from both the students and tutors point of view. Some students described being 'totally absorbed' in the process during the week. Tutors recognized the value that the 'total immersion' had on benefiting the concentration of the participating students and allowing for a performance to take place. However, students were more likely to view it as an additional bolt on to their profession specific curricula. In terms of the tutors' practical timetabling of rooms and theatre venues, it is easier to book rooms for a 1-week period rather than lots of separate days.

\section{Alternative models}

The alternative structure that both course teams considered was having five whole days integrated into all modules spaced out across the both programmes. This would still allow for shared learning but the value and importance of this element of their education might be enhanced if the students could 
see it as being fully integrated into both courses. The students would be able to use their ongoing and changing experiences of their practice placements during the MH sessions. Whether this might have an effect on the dilution of the existing high levels of concentration remains to be seen.

Another option might be to have had a week-long block integrated into one of the later shared modules. If this was the case, students might be more used to Masters level working, students would not lose the concentrated intensity, and practice placement experiences could be employed more effectively.

\section{Students learning about themselves}

A safe environment: $\mathrm{MH}$ work offers the students an opportunity to learn about themselves (Murray et al, 2000) It gives them a different type of learning experience which allows them to understand how they feel or might feel personally and professionally about different issues in different environments.

The structure provided the containment for the strong personal issues which emerged. Tutors offered space, time and ensured there was a safe environment in which the students could freely discuss issues. Tutors facilitated problem solving and group feedback skills to enhance this process. Students reflected well on their feelings and the therapeutic process but were less clear about what they had learnt and how this could be applied to future practice

The value of a 'performance': The inclusion of a performance supported and emphasized the dramatic nature of the week. McNaughton (2000) has explored how drama can demonstrate most effectively the nuances of communication between people both verbally and non verbally - a vital skill in health care.

The performance on the afternoon of the final day provided structure and containment to the week. Students felt it provided 'finality', 'closure' and 'brought the threads together'. Initial fears by the tutors that students might not learn their lines or suffer performance anxiety which might place additional pressure on the students did not materialize. There was no clear contract about the level or quality of the performance.

A small invited audience from the faculty of health attended and contributed to a 'post performance' discussion that overtly articulated an appreciation of the students' work and encouraged the students to explain their work and what they had learnt.

\section{The themes}

The tutors suggested suitable theme groups before the commencement of the week (e.g. social isolation, grief, old age, terminal illness). Students could then choose which theme group they worked in.
The themes were suitably broad but did not dovetail well with the introductory module that both the OTs and PTs were doing separately at that time. This strengthened the argument to move $\mathrm{MH}$ later in both programmes. This might also ensure that students would feel more confident and 'hooked into' the programme by then and feel confident enough by that stage not to stay within a theme group that might feel like a 'comfort zone' to them. Also more rehabilitation specific themes around the implications of occupational deprivation and chronic illness could be included.

For chronic illness in particular where biomedicine offers only a partial response rehabilitation professions can serve their users best by incorporating into their treatment/management an appreciation of the individual person's experience. This is supported by Evans and Greaves (1999) discussion of how a narrowly causal view of individual's illness and disability is inadequate in understanding the role of psychological factors and how these might fuse with more physical factors

\section{ACTION AND LEARNING POINTS}

After reviewing the $\mathrm{MH}$ week a number of action points were agreed.

\section{Students need to reflect on their own learning}

The educational curricula in OT and PT (CSP, 2002) and (COT, 2004) now have a greater emphasis on reflective practice, problem solving and lifelong learning to reflect the changing approach and philosophy of both professions. The OT and PT courses at Leeds Metropolitan University have reflected this by adopting a totally integrated problem-based learning approach to both curricula. Students are constantly encouraged to reflect on their individual, group and interpersonal skills as part of this process. This aims to encourage the concepts of respect, responsibility and empowerment, which are considered as essential for development of a sense of professional accountability.

In problem-based learning students are also presented with real-world 'problems', which provide the motivation and context for learning (Albanese and Mitchell, 1993; Duch et al, 2001). Complex physical and psychosocial issues are presented to them as problems on a weekly basis. However, the students, through the MH week, are given more time to engage emotionally with the issues and reflect more deeply on their own lives and actions and how they affect others.

Module tutors on both courses need to take the opportunity to remind the students of their $\mathrm{MH}$ week experiences and relate some of the week's themes to the problems and triggers used in their 
professional specific modules. For example, the tutors on the cardiovascular and respiratory PT module will use some of the literature and discussion points on bereavement and loss when discussing palliative care issues in this module.

\section{Clearer articulation of the need for reflection in the learning outcomes of the session}

The tutors will clearly articulate to the students that reflection on the learning outcomes of each session will occur. Formalized reflective frameworks (Johns 1995, Gibbs, 1988) will be provided as a structure for students to reflect on their own learning rather than just their feelings as a result of the therapeutic process.

\section{Enhance the importance and quality of the performance}

Clearer expectations about the performance will be articulated by the tutors. Students will be encouraged to learn their lines. There is recognition by the tutors that 5 days is not sufficient time to memorize large chunks of text but allows for brief quotes/passes to be learnt. The value of this is that participants can then move around the stage more freely as they are not holding scripts. Dramatic effect is emphasized, body language and physicality is improved and the meaning of the words are embodied and internalized. There will be a clear contract with the students about this at the beginning of the programme.

\section{Timing and length of the MH programme}

Tutors to give close consideration will be given to the format and timing of the $\mathrm{MH}$ work. Future weeks will take place later in the courses.

The range of themes used by the students would need to be reconsidered depending on the site of the $\mathrm{MH}$ teaching in the courses.

\section{CONCLUSION}

The MH week has been an innovative development for the PT and OT preregistration curricula at Leeds Metropolitan University. The aim is to continue modifying and improving it in response to the participants' evaluation. A more detailed evaluation of the development needs to be considered particularly linked to students' placement experiences, communication skills and their ability in their undertaking of critical reflection. IJTR

\footnotetext{
Conflict of interest: none.

Copyright permission obtained for use of U Fanthorpe's work by Peterloo Poets

Albanese M, Mitchell S (1993). Problem-based learning: A review of literature on its Outcomes and implementation. Academic Medicine 68(1): 52-81

Chartered Society of Physiotherapy (2002) The Curriculum
}

Framework for Qualifying Programmes in Physiotherapy.

Chartered Society of Physiotherapy (2003) Master's Level Programmes within Post-qualifying Physiotherapy Education: CSP Criteria and Expectations. CSP, London. http://www.csp.org.uk

Charon R, Traumann B, Connell JE (1995) Literature and Medicine: contributions to clinical practice. Anna Intern Med 122: 599-606

Chomsky N (1972) Language and Mind. New York University College of Occupational Therapists (COT) (2004) College of Occupational Therapists Curriculum Framework for Pre Registration Education. College of Occupational Therapists, London

De Villiers J (1993) Poetry and the Neurosurgeon. Acta Neurochirurgica 124: 166-7

Downie RS (2003) Medical Humanities: a vision and some cautionary notes. Medical Ethics: Med Humanities 29: 37-8

Duch B, Groh S, Allen D (Eds) (2001) The Power of Problembased Learning: A Practical 'How To' For Teaching Undergraduate Courses in Any Discipline. Sterling, Virginia: Stylus.

Evans M, Greaves D (1999) Exploring the Medical Humanities. BMJ 319: 1216

Fanthorpe UA (2005) Collected Poems 1973-2003. Peterloo Poets, Manchester

General Medical Council Education Committee (1993) Tomorrow's Doctors. GMC, London

Gibbs G (1988) Learning by Doing. FEU, Oxford

Gull S (2005) Embedding the Humanities into medical education. Med Educ 39: 235-6

Health Professions Council (HPC) Standards of Proficiency (2003) www.hpc-uk.org/publications/standards

Hill S (2005) In the Springtime of the Year. Penguin

Hunter K, Charon R, Coulehan JL (1995) The study of literature in medical education. Academic Medicine 70(9) 787-94

Hurwirz B (2003) Medicine, the arts and humanities. Clin Med 3: 497-8

Inskeep S, Lisko S (2001) Alternative clinical nursing experience in an art gallery. Nurse Educator 26(3): 117-9

Johns C (1995) The Value of Reflective Practice for Nursing. $J$ Clinical Nurs 4: 23-60

Lodge D (2002) Consciousness and the Novel. Secker \& Warburg: 7

McAteer M, Murray R (2003) The humanities in a course on loss and grief. Physiotherapy 89(2): 97-103

McNaughton J (2000) The Humanities in Medical Education: context, outcome and structure. Journal of Medical Ethics. Med Educ 26: 23-30

Murray R, McKay, Thompson S, Donald M (2000) Practising reflection: a medical humanities approach to Occupational Therapist education. Med Teach 22(3): 276-81

Robb and Murray (1992) Medical Humanities in nursing; thought provoking? J of Advanced Nursing 17(10): 1182-7

Staricoff RL (2004) Arts in health: A review of the medical literature. Arts Council. Report 36

\section{KEY POINTS}

- Including a period of medical humanities (MH) work within occupational therapy (OT) and physiotherapy (PT) preregistration education is a good way of encouraging empathy and self-reflection in the participating students.

- MH can complement the problem-based learning approach through its emphasis on team working skills, skill sharing, communication and reflection.

- A range of different $\mathrm{MH}$ models in relation to timing, format and length in courses may need to be considered to suit individual programme's needs and respond to ongoing feedback from participants.

- Students need a formalized framework and structure to allow them not just to reflect on their immediate feelings but on what they have learnt and how they might apply their learning to future practice.

- Using a 'performance' element helps to structure the learning, provide a forum for material to be synthesized and adds 'value' to the student's sense of self. 